\title{
Analisis Penyebab Kegagalan Penggunaan Sistem Informasi Manajemen Puskesmas (Simpus) dalam Penerimaan Pasien Rawat Jalan di Puskesmas Adimulyo Kabupaten Kebumen
}

\author{
Novi Dwi Christanti ${ }^{1}$, Rita Dian Pratiwi ${ }^{2}$ \\ Program Studi DIII Rekam Medis Sekolah Vokasi Universitas Gadjah Mada ${ }^{1,2}$ \\ vienovi26@gmail.com ${ }^{1}$, ritadianp@ugm.ac.id ${ }^{2}$
}

\begin{abstract}
ABSTRAK
Latar Belakang: Berdasarkan hasil studi pendahuluan di Puskesmas Adimulyo, SIMPUS tidak digunakan lagi dalam kegiatan pelayanan penerimaan pasien rawat jalan sejak tahun 2012 sampai sekarang. Selama ini kegiatan pelayanan penerimaan pasien rawat jalan di Puskesmas Adimulyo dilakukan secara manual, hal ini mengakibatkan proses kegiatan pelayanan membutuhkan waktu yang lama. Terutama pada saat proses pencarian nomor rekam medis pasien yang tidak membawa kartu berobat.

Tujuan: Menganalisis faktor-faktor penyebab kegagalan penggunaan Sistem Informasi Manajemen Puskesmas (SIMPUS) dalam kegiatan penerimaan pasien rawat jalan di Puskesmas Adimulyo.

Metode: Penelitian ini menggunakan metode penelitian deskriptif dengan jenis penelitian kualitatif dan rancangan penelitian fenomenologi. Subjek dalam penelitian ini adalah petugas penerimaan pasien rawat jalan dan objeknya SIMPUS. Teknik pengambilan datanya menggunakan wawancara, observasi dan studi dokumentasi. Teknik analasis data yang dilakukan peneliti meliputi tahap reduksi data, penyajian data dan menarik kesimpulan.

Hasil: Faktor-faktor yang menjadi penyebab tidak digunakannya SIMPUS adalah faktor man meliputi kurangnya dukungan dari kepala puskesmas dan kurangnya pemahaman petugas mengenai pentingnya penggunaan SIMPUS. Faktor method yaitu tidak adanya prosedur penggunaan SIMPUS pada penerimaan pasien rawat jalan.

Kesimpulan: Faktor-faktor yang menjadi penyebab tidak digunakannya SIMPUS dalam penerimaan pasien rawat jalan adalah faktor man (manusia) dan method (metode).

Kata Kunci: Analisis, SIMPUS, penerimaan pasien rawat jalan.
\end{abstract}

\section{ABSTRACT}

Background: Based on the first research at Adimulyo Primary Health Center, the researches got information that since 2012 Adimulyo Primary Health Center not use the primary health center information system also known as SIMPUS again for the outpatient services. Now the outpatient services use manual system, that use more time for the process. Especially for the process to search the patient's medical record number who are not carrying card medical treatment.

Objective: To analyze the factors that causes the failure of not using SIMPUS as system for outpatient admission services.

Methods: This research used descriptive research with qualitative research and phenomenological research design. The subjects were outpatients admissions officers and the object was SIMPUS. The technique of collecting data used interviews, observation and study documentation. Data analysis was conducted by the researcher including the step of data reduction, data presentation and drawin a coclusion.

Results: Factor that be the cause of the problem for not using SIMPUS is man's factors that the head of Adimulyo Primary Health Center was not given support about the important of using SIMPUS. The second factors is method factors because there is no procedure for using SIMPUS at Adimulyo Primary Health Center.

Conclusion: Factors that be the causes of the problem for not using SIMPUS are man and method. Keywords: Analysis, SIMPUS, patient's admission service 


\section{PENDAHULUAN}

Di era Jaminan Kesehatan Nasional $(\mathrm{JKN})$, pelayanan kesehatan tidak lagi terpusat di rumah sakit atau fasilitas kesehatan (faskes) tingkat lanjutan. Pelayanan kesehatan harus dilakukan secara berjenjang sesuai dengan kebutuhan medisnya mulai dari faskes primer seperti puskesmas atau klinik. Berdasarkan UU No. 36 tahun 2009 tentang kesehatan, untuk menyelenggarakan upaya kesehatan yang efektif dan efisien diperlukan informasi kesehatan. Informasi kesehatan yang dimaksud dilakukan melalui sistem informasi dan melalui lintas sektor.

Menurut Peraturan Pemerintah Republik Indonesia Nomor 46 tahun 2014 tentang Sistem Informasi Kesehatan bahwa Sistem Informasi Kesehatan wajib dikelola oleh Fasilitas Pelayanan Kesehatan untuk pengelolaan Sistem Informasi Kesehatan skala Fasilitas Pelayanan Kesehatan. Dengan adanya peraturan diatas maka Puskesmas harus menggunakan SIMPUS.

Berdasarkan hasil studi pendahuluan di Puskesmas Adimulyo, SIMPUS tidak digunakan lagi dalam kegiatan pelayanan penerimaan pasien rawat jalan. Selama ini kegiatan pelayanan penerimaan pasien rawat jalan di Puskesmas Adimulyo dilakukan secara manual, hal ini mengakibatkan proses kegiatan pelayanan membutuhkan waktu yang lama. Terutama pada saat proses pencarian nomor rekam medis pasien yang tidak membawa kartu berobat.

Berdasarkan latar belakang, maka rumusan masalah dalam penelitian ini adalah mengetahui faktor apa-saja yang menyebabkan kegagalan penggunaan Sistem Informasi Manajemen Puskesmas (SIMPUS) dalam penerimaan pasien rawat jalan di Puskesmas Adimulyo.

Tujuan umum dalam penelitian ini adalah menganalisis faktor-faktor penyebab kegagalan penggunaan Sistem Informasi Manajemen Puskesmas (SIMPUS) dalam kegiatan penerimaan pasien rawat jalan di Puskesmas Adimulyo. Tujuan khusus dalam penelitian ini adalah mengetahui proses pelayanan penerimaan pasien rawat jalan, mengetahui faktor-faktor penyebab tidak digunakannya Sistem Informasi Manajemen Puskesmas (SIMPUS) dalam kegiatan pelayanan penerimaan pasien rawat jalan, membuat alternatif solusi agar SIMPUS bisa digunakan kembali dalam kegiatan penerimaan pasien rawat jalan.

\section{METODE}

Jenis penelitian pada penelitian ini menggunakan metode penelitian deskriptif dengan jenis penelitian kualitatif dan menggunakan rancangan penelitian fenomenologi.

Subjek penelitian dalam penelitian ini yaitu petugas penerimaan pasien rawat jalan di Puskesmas Adimulyo sebanyak 2 petugas, sedangkan objek dalam penelitian ini adalah Sistem Informasi Manajemen Puskesmas (SIMPUS) pada bagian penerimaan pasien rawat jalan di Puskesmas Adimulyo.

Instrumen pengumpulan data yang digunakan dalam penelitian ini adalah pedoman wawancara, check list observasi, check list studi dokumentasi, alat tulis, alat perekam suara.

Teknik analisis data yang digunakan oleh peneliti adalah reduksi data, penyajian data, menarik kesimpulan.

\section{HASIL \& PEMBAHASAN}

\section{A. Hasil}

Penerimaan pasien rawat jalan di Puskesmas Adimulyo dilakukan secara manual dan komputerisasi. Jumlah petugas penerimaan pasien rawat jalan di Puskesmas Adimulyo berjumlah 2 orang dengan kualifikasi SLTA.

Software yang digunakan oleh Puskesmas Adimulyo untuk melakukan penerimaan pasien rawat jalan adalah SIKDA (Sistem Informasi Kesehatan Daerah), tetapi karena ada beberapa faktor maka SIKDA ini tidak digunakan lagi. SIKDA terdiri dari beberapa aplikasi yang salah satunya adalah SIMPUS. Puskesmas Adimulyo bertahan selama 2 tahun menggunakan SIMPUS sejak diwajibkannya pengoperasian SIMPUS. Puskesmas menggunakan SIMPUS sejak tahun 2010-2012, setelah itu Puskesmas 
kembali dengan menggunakan cara manual.

Puskesmas Adimulyo menggunakan sistem penomoran UNS (Unit Numbering System) dimana setiap pasien yang datang berobat akan mendapatkan nomor rekam medis yang akan digunakan untuk selamanya. Selain itu puskesmas juga menggunakan pendekatan family folder, sehingga setiap satu keluarga menggunakan satu nomor rekam medis.

Berikut adalah alur penerimaan pasien rawat jalan baru untuk petugas dan juga pasien rawat jalan di Puskesmas Adimulyo Kabupaten Kebumen:

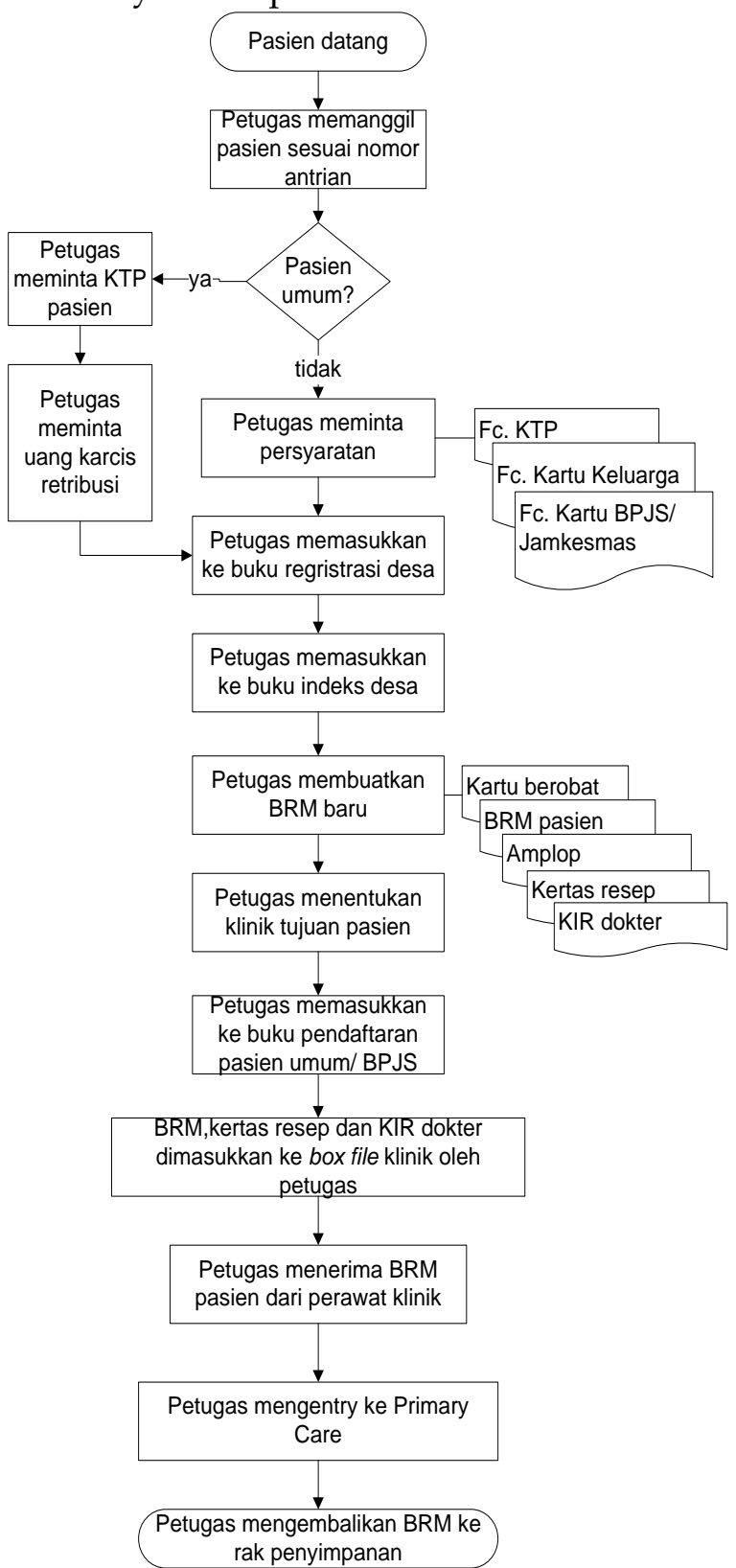

Gambar 1. Alur Penerimaan Pasien Rawat Jalan Baru Untuk Petugas di Puskesmas Adimulyo

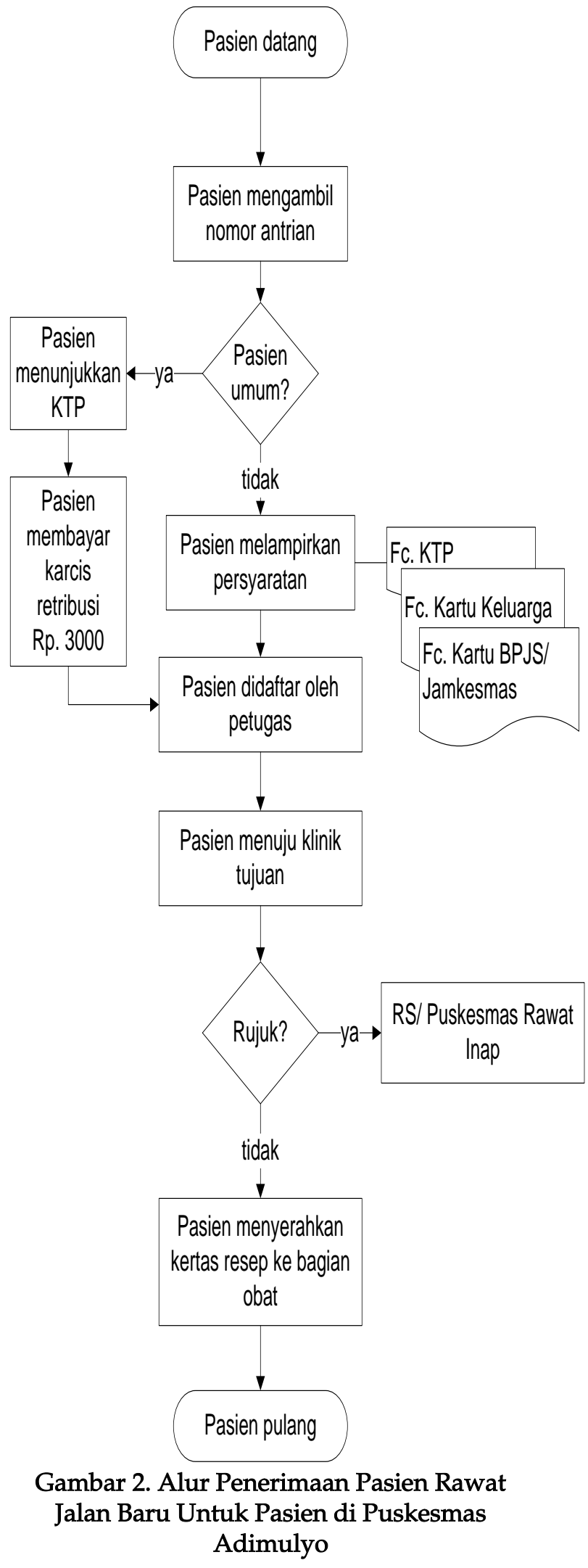

Berikut adalah alur penerimaan pasien rawat jalan lama untuk petugas dan juga pasien rawat jalan di Puskesmas Adimulyo Kabupaten Kebumen: 
Analisis Penyebab Kegagalan Penggunaan Sistem Informasi Manajemen...
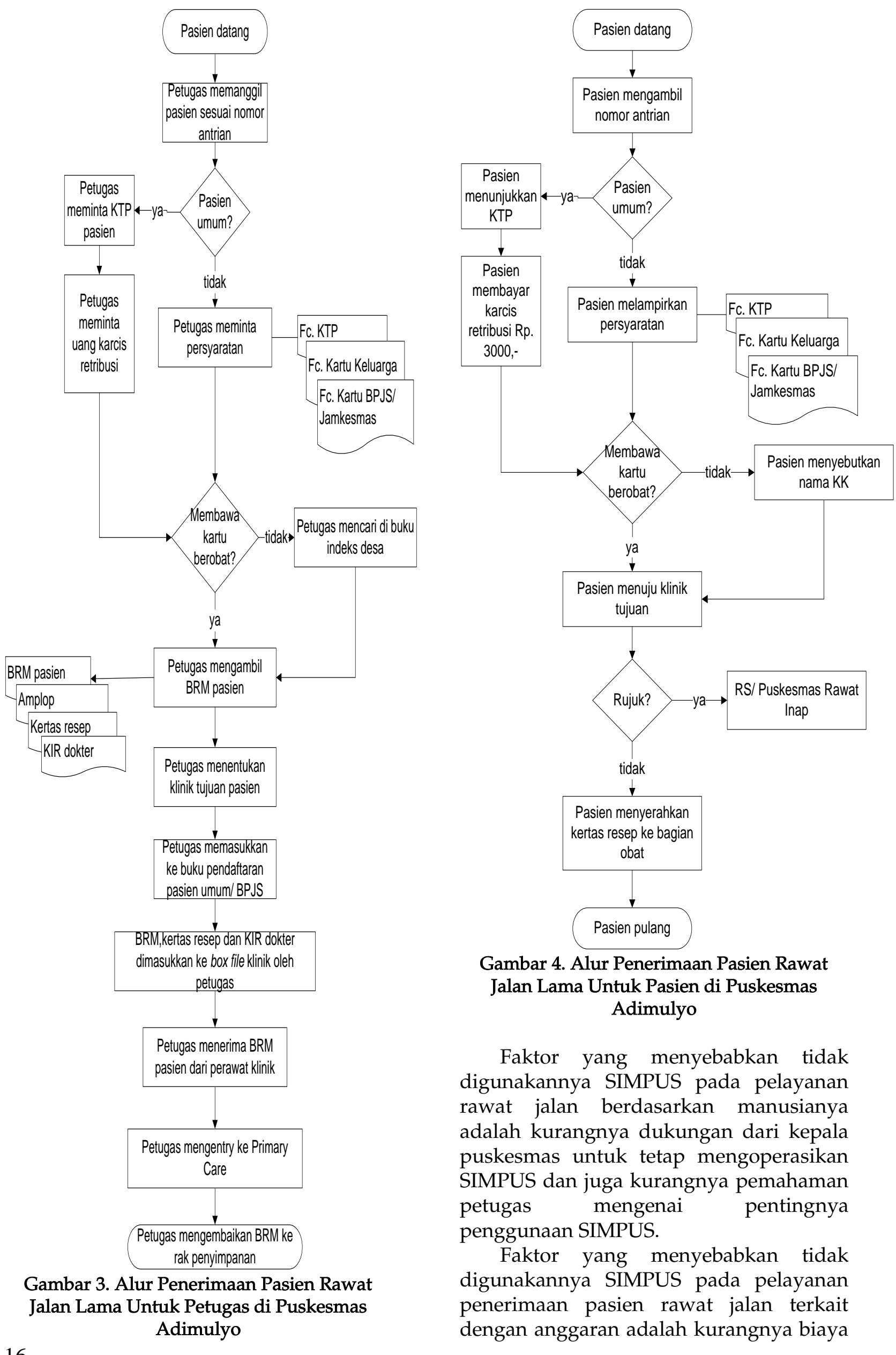

\section{Gambar 4. Alur Penerimaan Pasien Rawat Jalan Lama Untuk Pasien di Puskesmas Adimulyo}

Faktor yang menyebabkan tidak digunakannya SIMPUS pada pelayanan rawat jalan berdasarkan manusianya adalah kurangnya dukungan dari kepala puskesmas untuk tetap mengoperasikan SIMPUS dan juga kurangnya pemahaman petugas mengenai pentingnya penggunaan SIMPUS.

Faktor yang menyebabkan tidak digunakannya SIMPUS pada pelayanan penerimaan pasien rawat jalan terkait dengan anggaran adalah kurangnya biaya 
untuk pengadaan perangkat yang mendukung pengoperasian SIMPUS.

Faktor yang menyebabkan tidak digunakannya SIMPUS pada pelayanan penerimaan pasien rawat jalan terkait dengan materialnya adalah sarana dan prasarananya belum mendukung untuk pengoperasian SIMPUS.

Faktor yang menyebabkan tidak digunakannya SIMPUS dalam pelayanan penerimaan pasien rawat jalan terkait dengan mesinnya tidak ada.

Faktor yang menyebabkan tidak digunakannya SIMPUS dalam pelayanan penerimaan pasien rawat jalan terkait dengan metode adalah tidak adanya prosedur penggunaan SIMPUS pada penerimaan pasien rawat jalan.

Berikut adalah identifikasi alternatif solusi yang dibuat oleh peneliti:

Tabel 1. Identifikasi Alternatif Solusi

\begin{tabular}{|c|c|c|c|}
\hline No. & Unsur 5M & Permasalahan & Alternatif Solusi \\
\hline 1. & Man & $\begin{array}{l}\text { Kurangnya pemahaman } \\
\text { petugas mengenai pentingnya } \\
\text { penggunaan SIMPUS }\end{array}$ & $\begin{array}{l}\text { Kepala Puskesmas memberikan } \\
\text { dukungan dengan membuat } \\
\text { kebijakan mengenai pengoperasian } \\
\text { SIMPUS } \\
\text { Diadakannya pelatihan mengenai } \\
\text { SIMPUS khusus petugas yang } \\
\text { melakukan penerimaan pasien rawat } \\
\text { jalan }\end{array}$ \\
\hline 2. & Money & $\begin{array}{l}\text { Kurangnya biaya untuk } \\
\text { pengadaan perangkat yang } \\
\text { mendukung pengoperasian } \\
\text { SIMPUS }\end{array}$ & $\begin{array}{l}\text { Pengajuan anggaran untuk } \\
\text { pembelian modem dan pulsanya } \\
\text { Pengajuan anggaran untuk } \\
\text { pembelian penguat sinyal yang lebih } \\
\text { jauh jangkauannya } \\
\text { Pengajuan anggaran untuk } \\
\text { pengadaan wifi }\end{array}$ \\
\hline 3. & Material & $\begin{array}{l}\text { Sarana dan prasarana belum } \\
\text { lengkap }\end{array}$ & $\begin{array}{l}\text { Mengonfirmasi ulang ke } \\
\text { Dishubkominfo mengenai } \\
\text { infastuktur tower } \\
\text { Pengadaan modem baru } \\
\text { Pengadaan penguat sinyal yang lebih } \\
\text { luas jangkauannya } \\
\text { Pengajuan untuk pengadaan wifi } \\
\text { Menggunakan satu komputer untuk } \\
\text { mengoperasikan SIMPUS dan P-Care }\end{array}$ \\
\hline 4. & Method & $\begin{array}{l}\text { Tidak adanya prosedur } \\
\text { penggunaan SIMPUS pada } \\
\text { penerimaan pasien rawat jalan }\end{array}$ & $\begin{array}{l}\text { Pembuatan prosedur penerimaan } \\
\text { pasien rawat jalan menggunakan } \\
\text { SIMPUS }\end{array}$ \\
\hline
\end{tabular}

\section{B. Pembahasan}

Software yang digunakan oleh Puskesmas Adimulyo untuk penerimaan pasien rawat jalan adalah SIKDA (Sistem Informasi Kesehatan Daerah). SIKDA terdiri dari beberapa aplikasi yaitu mencakup SIMPUS, SPTP, SIMO dan SIMKA (Modul Manual SIMPUS, 2009).

Puskesmas Adimulyo menggunakan sistem penomoran UNS (Unit Numbering System). Menurut Huffman (1994) bahwa pada penomoran unit, pasien pada admission pertama diberikan nomor yang dipertahankan pada seluruh kunjungan dan pengobatan selanjutnya. Pada sistem penomoran unit ini pasien akan mendapatkan satu nomor rekam medis ketika pasien tersebut pertama kali datang dan tercatat sebagai pasien di fasilitas pelayanan kesehatan tersebut. Nomor rekam medis ini dapat dipergunakan untuk semua pelayanan kesehatan yang ada difasilitas pelayanan rawat jalan.

Kelebihan pada sistem penomoran unit adalah informasi klinis dapat berkesinambungan karena semua data dan informasi mengenai pasien dan pelayanan yang diberikan berada dalam 
satu berkas. Sedangkan kekurangannya adalah untuk pelayanan pasien lama akan lebih lama karena pada pasien lama akan dicarikan berkas rekam medisnya yang lama setelah berkasnya ketemu selanjutnya pasien baru akan mendapatkan pelayanan.

Dalam pelaksanaan penerimaan pasien rawat jalan, pasien sering tidak mengambil nomor antrian terlebih dahulu dikarenakan tidak adanya tulisan atau alur yang menyatakan bahwa pasien wajib mengambil nomor antrian terlebih dahulu sebelum melakukan pendaftaran. Akibat dari tidak adanya nomor antrian ini adalah ada kemungkinan pasien akan dilayani tidak sesuai dengan waktu kedatangannya. Selain itu juga dapat mengakibatkan pelayanan penerimaan pasien rawat jalan tidak rapi karena setiap pasien pasti ingin dilayani secepatnya. Dengan adanya nomor antrian, maka penumpukan pasien dapat terhindarkan dan juga pasien menjadi lebih tertib.

Maka dari itu dibutuhkannya tulisan yang menyatakan pasien harus mengambil nomor antrian terlebih dahulu atau membuat alur yang mudah dipahami oleh pasien. Alur pasien menggambarkan tentang bagan tahapan pelayanan dari awal pasien datang sampai pelayanan berakhir atau pulang dari suatu fasilitas pelayanan kesehatan (Budi, 2011).

Dengan adanya alur maka diharapkan pasien mengetahui bagaimana alur pelayanan yang ada di Puskesmas Adimulyo. Selain alur yang harus mudah dipahami pasien, letak alurnya tersebut juga harus diperhatikan. Sebaiknya letak alur pelayanan pasien rawat jalan diletakkan di dekat pintu masuk Puskesmas Adimulyo. Hal ini dikarenakan agar pasien sebelum masuk ke puskesmas dapat membaca atau melihat alur pelayanan terlebih dahulu.

Kartu berobat merupakan alat yang sangat diperlukan untuk pencarian nomor rekam medis pasien lama. Dalam pelaksanaan penerimaan pasien masih banyak pasien yang sering tidak membawa kartu berobat. Karena pendaftaran pasien masih manual maka jika pasien tidak membawa kartu berobat, petugas mencari nomor rekam medis di buku indeks desa berdasarkan nama KK pasien. Fungsi buku indeks desa ini serupa dengan KIUP, hanya saja KIUP memiliki manfaat lebih dari buku indeks desa.

KIUP merupakan kepanjangan dari Kartu Indeks Utama Pasien. Menurut Hatta (2010) indeks ini merupakan kunci untuk mengetahui data identitas sosial pasien yang digunakan dalam pelayanan kesehatan. Indeks ini sama-sama berfungsi sebagai referensi identitas utama pasien yang wajib dibuat dalam setiap bentuk pelayanan kesehatan (puskesmas, rumah sakit dan lainnya) dan bersifat permanen. Fungsi indeks amat terasa bagi pasien terutama di saat pasien tidak membawa kartu berobat. Sedangkan bagi kepentingan administratif, data sosialnya amat berguna bagi berbagai kepentingan manajemen. KIUP hanya dibuat di saat pasien pertama kalinya terdaftar di sarana pelayanan kesehatan tersebut.

Menurut Hatta (2010) setiap fasilitas pelayanan kesehatan rumah sakit maupun puskesmas harus membuat kebijakan dan prosedur sesuai dengan tenaga dan fasilitas yang dimilikinya. Kebijakan dan prosedur tersebut merupakan pedoman bagi petugas agar dapat melaksanakan kegiatan penerimaan pasien rawat jalan dengan konsisten.

Kegiatan di tempat penerimaan pasien belum ada prosedur yang tertulis. Sebaiknya prosedur penerimaan dibuat tertulis karena hal ini dilakukan untuk mengontrol pekerjaan yang telah dilakukan sehingga pekerjaan yang dilakukan dapat konsisten dan sesuai aturan. Selain itu prosedur juga diletakkan di tempat yang mudah dibaca oleh petugas penerimaan pasien karena prosedur merupakan serangkaian langkah yang saling terhubung sebagai pedoman pekerjaan sehingga mencapai tujuan yang telah ditentukan.

Masalah yang terjadi di Puskesmas Adimulyo ini adalah tidak digunakannya SIMPUS dalam kegiatan penerimaan pasien rawat jalan. Dengan adanya Peraturan Pemerintah Republik Indonesia 
Nomor 46 tahun 2014 tentang Sistem Informasi Kesehatan dan juga demi terwujudnya sistem yang terintegrasi maka Puskesmas wajib untuk mengoperasikan SIMPUS. Berikut adalah analisis sebab akibat faktor- faktor yang menyebabkan tidak digunakannya SIMPUS dalam penerimaan pasien rawat jalan di Puskesmas Adimulyo:

Berikut adalah gambar diagram tulang ikan (Fishbone Diagram) yang menunjukkan faktor-faktor yang menyebabkan tidakdigunakannya SIMPUS dalam penerimaan pasien rawat jalan di Puskesmas Adimulyo:

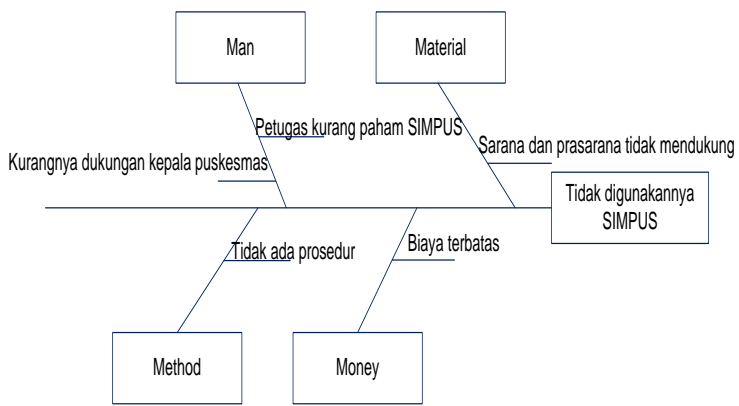

\section{Gambar 5. Faktor-Faktor PenyebabTidak Digunakannya SIMPUS di Puskesmas Adimulyo}

Berdasarkan hasil penelitian peneliti menemukan beberapa faktor yang menyebabkan SIMPUS di Puskesmas Adimulyo tidak digunakan lagi. Dilihat dari faktor manusianya, faktor penyebab tidak digunakannya SIMPUS adalah sebagai berikut:

$\begin{array}{lcr}\text { 1. Kurangnya dukungan } & \text { kepala } \\ \text { puskesmas } & \text { untuk tetap }\end{array}$
mengoperasikan SIMPUS

Menurut Ladjamudin (2005), salah satu komponen membentuk sistem informasi yang baik adalah komponen people dan procedures yang mengatur manusia dan tata cara menggunakan sistem tersebut. Prosedur di Puskesmas Adimulyo belum ada. Agar pelayanan penerimaan pasien rawat jalan dengan SIMPUS berjalan dengan baik, maka diperlukannya Kepala Puskesmas Adimulyo untuk membuat kebijakan yang mendukung pengoperasian SIMPUS. Dengan adanya dukungan dari Kepala Puskesmas Adimulyo maka diharapkan pengoperasian SIMPUS akan tetap terlaksana.

2. Kurangnya pemahaman petugas mengenai pentingnya penggunaan SIMPUS

Berdasarkan hasil wawancara dengan salah satu petugas penerimaan pasien rawat jalan di Puskesmas Adimulyo bahwa dapat disimpulkan bahwa petugas belum memahami peranan SIMPUS dan juga Primary Care. Petugas beranggapan bahwa Primary Care itu adalah penggantinya SIMPUS. Anggapan tersebut salah karena SIMPUS dan Primary Care merupakan 2 program yang seharusnya saling terintegrasi.

Berdasarkan hasil penelitian, peneliti menemukan faktor penyebab tidak digunakannya SIMPUS terkait anggaran yaitu kurangnya biaya untuk pengadaan perangkat yang mendukung pengoperasian SIMPUS. Di Puskesmas adimulyo ini tidak ada biaya khusus untuk pelaksanaan pengoperasian SIMPUS. Perangkat yang mendukung pengoperasian SIMPUS yaitu modem, tetapi puskesmas tidak memiliki biaya yang cukup untuk pengadaan modem tersebut.

Dalam satu komputer dapat mengoperasikan SIMPUS dan P-Care, sehingga puskesmas tidak perlu mengeluarkan biaya untuk pengadaan modem lagi karena mengingat anggaran untuk mendukung pengoperasian SIMPUS ini terbatas. Maka dari itu, pada faktor money ini tidak perlu dipermasalahkan karena modem satu cukup untuk mengoperasikan SIMPUS dan juga P-Care.

Berdasarkan hasil penelitian peneliti menemukan beberapa faktor yang menyebabkan SIMPUS di Puskesmas Adimulyo tidak digunakan lagi. Faktor penyebab tidak digunakannya SIMPUS adalah sarana dan prasarana belum mendukung untuk pengoperasian SIMPUS.

Sarana dan prasarana yang 
mendukung pengoperasian SIMPUS yaitu infrastruktur tower atau modem. Infrastruktur tower tersebut dulunya dikelola oleh Dinas Kesehatan Kabupaten Kebumen, tetapi karena tidak adanya biaya pemeliharaan sehingga untuk sekarang ini diambil alih oleh DISHUBKOMINFO. Dengan demikian untuk saat ini, Puskesmas tidak menggunakan tower lagi, tetapi menggunakan modem.

Modem yang ada di Puskesmas Adimulyo hanya satu, sedangkan program yang membutuhkan modem ada 2 yaitu program SIMPUS dan $P$ Care. Modem merupakan perangkat keras yang berfungsi untuk menyambungkan kita pada internet. Selain itu, modem juga berfungsi untuk komunikasi dua arah yang merubah sinyal digital menjadi sinyal analog atau sebaliknya untuk mengirimkan pesan atau data ke alamat yang dituju dan bisa juga diartikan sebagai perantara untuk menghubungkan komputer kita ke jaringan internet.

Modem yang dimaksud adalah modem eksternal, modem tersebut dipasang di luar komputer yang biasanya ditancapkan di slot USB (Universal Serial Bus). Dengan adanya modem satu lagi maka petugas dapat mengoperasikan SIMPUS kembali, tetapi dalam hal ini puskesmas tidak memiliki biaya untuk pengadaan modem lagi. Menurut pertimbangan peneliti, penggunaan modem cukup satu pada satu komputer, karena dalam satu komputer dapat mengoperasikan 2 aplikasi yaitu SIMPUS dan P-Care. Sehingga pada material ini tidak dipermasalahkan karena modem satu pun cukup untuk mengoperasikan SIMPUS dan P-Care.

Dalam penelitian ini keadaan komputer yang digunakan untuk penerimaan pasien rawat jalan di Puskesmas Adimulyo tidak bermasalah.
Berdasarkan hasil penelitian peneliti menemukan faktor yang menyebabkan SIMPUS di Puskesmas Adimulyo tidak digunakan lagi. Faktor penyebab tidak digunakannya SIMPUS adalah tidak adanya prosedur penggunaan SIMPUS pada penerimaan pasien rawat jalan. Tidak adanya prosedur ini karena Puskesmas Adimulyo belum pernah melakukan Akreditasi. Rencana akan dilakukannya akreditasi yaitu pada tahun 2017. Dengan adanya prosedur maka petugas dapat melaksanakan kegiatan penerimaan pasien rawat jalan secara konsisten dan sesuai aturan.

Berdasarkan pengidentifikasian solusi maka peneliti memilih solusi yang menurut peneliti solusi tersebut adalah solusi yang terbaik untuk menyelesaikan permasalahan tidak digunakannya SIMPUS dalam penerimaan pasien rawat jalan di Puskesmas Adimulyo. Berikut solusisolusi yang terpilih untuk dijadikan alternatif solusi:

1. Diadakannya pelatihan mengenai SIMPUS khusus petugas yang melakukan penerimaan pasien rawat jalan

Menurut Hatta (2010) manfaat pendidikan dan pelatihan dapat membantu organisasi dalam mencapai tujuan, baik bagi individu, kelompok maupun organisasi. Pelatihan mengenai SIMPUS ini penting agar petugas penerimaan pasien rawat jalan di Puskesmas Adimulyo tidak keliru tentang pemahaman SIMPUS dan juga $P$-care. Program-program tersebut wajib untuk dioperasikan secara beriringan agar terciptanya informasi yang terintegrasi antara SIMPUS dan $P$ care.

2. Menggunakan satu komputer untuk mengoperasikan SIMPUS dan $P$-Care

Dengan menggunakan satu komputer untuk mengoperasikan SIMPUS dan P-Care pada saat penerimaan pasien rawat jalan di Puskesmas Adimulyo, maka 
puskesmas tidak perlu mengeluarkan biaya untuk pembelian modem lagi. Selain itu, pelayanan akan lebih efisien waktu pada saat petugas melakukan entry data ke aplikasi $P$ Care. Hal tersebutdikarenakan petugas dapat mengnyalin entry-an data yang sudah diinputkan ke SIMPUS lalu di pindahkan P-Care, sehingga petugas tidak perlu untuk mengetik kembali data yang seharusnya dientrykan ke $P$-Care.

3. Pembuatan prosedur penerimaan pasien rawat jalan menggunakan SIMPUS

Dengan adanya prosedur penerimaan pasien rawat jalan baru dan lama dengan menggunakan SIMPUS ini maka kegiatan penerimaan pasien rawat jalan bisa lebih tertata dan juga konsisten.

\section{PENUTUP}

\section{A. Kesimpulan}

1. Pada proses penerimaan pasien rawat jalan ini ada beberapa permasalah yaitu banyak pasien yang tidak mengambil nomor antrian, tidak adanya alur penerimaan pasien rawat jalan, banyak pasien yang tidak sadar akan pentingnya pasien membawa kartu berobat dan tidak adanya prosedur penerimaan pasien rawat jalan.

2. Faktor-faktor yang menjadi penyebab tidak digunakannya SIMPUS dalam penerimaan pasien rawat jalan di Puskesmas Adimulyo diantaranya faktor man (manusia) dan method (metode).

3. Solusi yang terpilih untuk menyelesaikan permasalahan tidak digunakannya SIMPUS dalam penerimaan pasien rawat jalan di Puskesmas Adimulyo yaitu diadakannya pelatihan mengenai SIMPUS khusus petugas yang melakukan penerimaan pasien rawat jalan, menggunakan satu komputer untuk mengoperasikan SIMPUS dan $P$-Care dan juga pembuatan prosedur penerimaan pasien rawat jalan dengan menggunakan SIMPUS.
B. Saran

1. Sebaiknya nomor antrian diletakkan di tempat yang mudah dilihat oleh pasien yang baru memasuki puskesmas, selain itu juga diberikan tulisan yang besar berisikan kata-kata yang mewajibkan pasien mengambil nomor antrian terlebih dahulu.

2. Sebaiknya dibuatkan alur penerimaan pasien rawat jalan yang mudah dipahami pasien dan diletakkan di depan pintu masuk puskesmas agar pasien paham harus kemana dahulu.

3. Sebaiknya buku indeks desa diganti dengan KIUP agar petugas tidak merasa kesulitan saat pencarian nomor rekam medis pasien yang tidak membawa kartu berobat.

4. Sebaiknya diadakan pelatihan kembali mengenai SIMPUS dan Primary Care khusus petugas penerimaan pasien.

\section{DAFTAR PUSTAKA}

Budi, S.C. (2011). Manajemen Unit Kerja Rekam Medis. Yogyakarta: Quantum Sinergis Media.

$\begin{array}{ccc}\text { Departemen } & \text { Kesehatan } & \text { RI. } \\ \text { Pedoman } & \text { Sistem } & \text { Informasi } \\ \text { Manajemen } & \text { Puskesmas. } & \text { Jakarta: }\end{array}$ Depkes RI.

Dinas Kesehatan Kabupaten Kebumen Propinsi Jawa Tengah. (2009). Manual SIMPUS (Sistem Informasi Manajemen Puskesmas). Pelatihan SIMPUS. 2009, Kebumen, Indonesia.Hal IV.

Hatta, G. R. (2010). Pedoman Manajemen Informasi Kesehatan di Sarana Pelayanan Kesehatan. Jakarta: UIPress.

Huffman, E.K. (1994). Health Information Management, Tenth Edition. Illionis: Physician Record Company.

Ladjamudin, A.-B.B. (2005). Analisis dan Desain Sistem Informasi. Yogyakarta: Graha Ilmu.

Peraturan Pemerintah Republik Indonesia No. 46 Tahun 2014 Tentang Sistem Informasi Kesehatan. www.kemkes.go.id. Diakses tanggal 15 Febuari 2016 